\title{
Quantium: um objeto de aprendizagem sobre o uso da linguagem em gêneros textuais emergentes
}

\author{
Raquel Santiago Freire², Carolina Morais R. Silva1, Amanda L. Girão1, M Alinne \\ F. de Brito ${ }^{1}$ Rayssa A. Hitzschky ${ }^{1}$, Cintia A. Lima ${ }^{1}$, Fernando A. B. dos Santos \\ Junior ${ }^{1}$, José Nery de Lima Filho ${ }^{1}$, João Everton L. Cavalcante ${ }^{1}$, J. Aires de Castro \\ Filho $^{2}$ \\ ${ }^{12}$ Instituto UFC Virtual - \\ Universidade Federal do Ceará (UFC) Campus do Pici - Bloco $901-1^{\circ}$ andar - CEP \\ 60455-760 - Fortaleza - CE

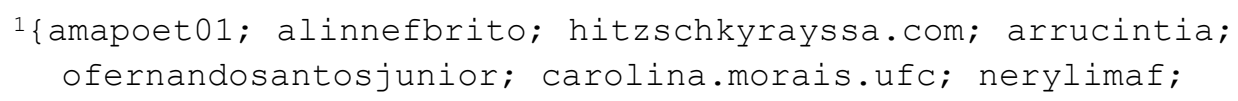

Resumo. $O$ artigo discorre sobre o processo de desenvolvimento do objeto de aprendizagem (OA) Quantium, que objetiva ajudar professores e alunos a refletir sobre o uso de gêneros textuais emergentes em ferramentas de comunicação instantânea. O OA está sendo desenvolvido em HTML 5, com folha de estilo em CSS3, baseou-se em métodos de design de interfaces realizando uma pesquisa com uma amostra de 40 estudantes do $8^{\circ}$ e $9^{\circ}$ anos de uma escola da rede pública de ensino, para descobrir as preferências dos alunos em estilos de jogos, gêneros e personagens favoritos. As ações dos botões e da tela foram todas programadas usando Javascript. O recurso poderá ser usado por professores e alunos visando favorecer a reflexão sobre as formas atuais de utilização da linguagem e o uso do internetês.

\begin{abstract}
The paper discusses the development process of the learning object (LO) QUANTIUM, which aims to help teachers and students to reflect on the use of emerging genres in instant communication tools. The LO is being developed in HTML5 with CSS3 style sheet, was based on interface design methods conducting a survey with a sample of 40 students, from the 8th and 9th grades of a public school to find out their preferences concerning game styles, genres and favorite characters. The actions of the buttons and the screen were all programmed using Javascript. The feature will be use by teachers and students aiming to promote reflection on the current forms of language use and the use of "internetês", a language code which has been used in digital genres.
\end{abstract}


V Congresso Brasileiro de Informática na Educação (CBIE 2016)

Anais dos Workshops do V Congresso Brasileiro de Informática na Educação (CBIE 2016)

\section{Cenário de Uso}

Atualmente, através da Internet, as pessoas estão se comunicando cada vez mais e de forma mais rápida, trazendo várias modificações e desdobramentos à linguagem. Desta maneira, constantemente estamos criando formas de dinamizar o processo de conversação, passando a usar abreviações, reduzir ou aumentar fonemas e até mesmo subtrair pontuação e acentuação.

Esta nova prática de escrita é caracterizada pelo registro divergente da norma culta padrão, mais conhecida como internetês ou netspeak, uma forma grafolinguística que se difundiu nos bate papos, blogs e redes sociais (KOMESU; TENANI, 2009, ARAÚJO, 2007). Os dois termos, internetês e netspeak diferem-se apenas pelos contextos culturais nos quais se encontram, respectivamente as Línguas Portuguesa e Inglesa. Ambos podem ser considerados muito mais que uma forma de se comunicar no mundo digital. Dizem respeito à textos eletrônicos simultâneos fluidos, que transcendem o limite tradicional incutido no texto escrito. Ampliam as possibilidades de comunicação no meio virtual, pois há a possibilidade de inserção de links, o que torna essa linguagem hipermidiática (CRYSTAL, 2005).

Muitos estudos têm discutido este fenômeno, buscando entender sua prática e utilização (CRYSTAL, 2005, MARCUSCHI, 2003, CHACON, 1998). Eles defendem a necessidade de compreender que, atualmente, existem diversas línguas: a língua falada, a escrita, e a digital. Nossa forma de nos expressar não é igual em todas essas modalidades. Assim como a língua falada não é igual à língua escrita, a digital também não é.

O trabalho com os gêneros textuais digitais em Língua Portuguesa é algo recente, sendo o internetês discutido em pesquisas acadêmicas (FUSCA, 2008), porém pouco vemos sua aplicação no contexto escolar. É necessário integrar nas atividades escolares, a compreensão de que a língua está dentro de um contexto histórico-social e que sua constituição é híbrida, ou seja, faz-se a partir de diferentes elementos que compõem a situação linguística comunicacional.

Com objetivo de refletir sobre as formas atuais de utilização da linguagem e o uso do internetês no contexto escolar, o Grupo de Pesquisa e Produção em Ambientes Interativos e Objetos de Aprendizagem (PROATIVA) está desenvolvendo um objeto de aprendizagem, denominado Quantium ${ }^{1}$ para ser usado por professores de Língua Portuguesa com estudantes dos anos finais do Ensino Fundamental. Portanto, o objetivo do OA em desenvolvimento é mostrar, através de um jogo de investigação, como podemos nos comunicar de forma escrita, dependendo do contexto no qual nos encontramos.

As atividades do Quantium se propõem a servir de orientação para o professor que objetiva trabalhar com a retextualização (escrita de um texto a partir de um ou mais textos), através da transmutação ${ }^{2}$ de gêneros em Língua Portuguesa, visto que a contextualização é primordial para o funcionamento pleno da língua em contexto real.

\footnotetext{
${ }^{1}$ Para acessar o protótipo: www.proativa.virtual.ufc.br/quantium. Vídeo: https://youtu.be/Fp2dv4rLBNs ${ }^{2}$ De acordo com Zavam (2012, p.257), seria esse "fenômeno que regeria a possibilidade de transformar e ser transformado a que os gêneros do discurso estariam inexoravelmente submetidos"
} 
V Congresso Brasileiro de Informática na Educação (CBIE 2016)

Anais dos Workshops do V Congresso Brasileiro de Informática na Educação (CBIE 2016)

\section{Desenvolvimento}

Após decidir a temática do OA e antes de começar o processo de desenvolvimento, a equipe se reuniu para decidir o público-alvo que se desejava atingir. Como o OA faz uso de questões que envolvem a linguagem e a comunicação de caráter imediato, optou- se por trabalhar com os alunos dos anos finais do Ensino Fundamental, visto que eles já possuem um maior domínio de diferentes estruturas linguísticas em contextos comunicacionais diversos quando comparados aos alunos dos anos iniciais.

Posteriormente, foi realizada uma pesquisa em uma escola da rede pública de ensino, com 40 estudantes do Ensino Fundamental em duas turmas do $8^{\circ}$ e $9^{\circ}$ anos. Utilizou-se um formulário impresso com o intuito de descobrir as preferências dos alunos em estilos de jogos, gêneros e personagens, de maneira que a criar a narrativa e comunicação visual do OA para melhor atender ao público-alvo.

Após essa etapa, houve reuniões semanais com a equipe pedagógica e técnica para definição da narrativa e interações que deveriam compor o OA. Seguiu-se, então, para a parte de prototipagem das primeiras telas e definição da identidade visual do recurso.

A história acontece em uma cidade chamada Quantium. A narrativa do OA apresenta uma bactéria que contaminou a cidade sendo sua causa ainda desconhecida. Sabe-se apenas que as pessoas estão sendo infectadas e estão perdendo a capacidade de se comunicar, transformando-se em uma espécie de zumbis. O usuário, um cientista ainda estagiário, deverá ajudar no procedimento de elaboração de um antídoto para salvar a cidade.

Para isso, é necessário que seja estabelecida a comunicação com 04 (quatro) pessoas, sendo elas: (1) a bibliotecária, que, por encontrar-se na biblioteca da cidade, auxiliará no compartilhamento de um livro contendo a fórmula do antídoto; (2) um professor universitário que escreveu um artigo que são citados os instrumentos de laboratório necessários para produzir o antídoto, além de temperatura ideal e estado que o antídoto deve permanecer; (3) o farmacêutico, que possui as bulas de um remédio específico, cujos nomes dos seus componentes químicos são necessários para a elaboração do antídoto e, (4) o agrônomo, que se encontra em uma fazenda e possui uma espécie de planta briófita também necessária para a fabricação do contraveneno.

No que concerne ao design, o estilo visual foi definido a partir da pesquisa realizada com os estudantes que apontou o gênero terror como o preferido. As ilustrações e as telas foram feitas com a utilização do programa de edição Adobe Photoshop juntamente com o Adobe Illustrator. Primeiramente, foram feitos protótipos de tela no papel, seguidos por protótipos de tela de baixa fidelidade, utilizando o Illustrator. Os últimos protótipos, com ilustrações, foram criados fazendo-se uso dos dois programas (Photoshop e Illustrator).

O código do OA foi desenvolvido com o auxílio do editor de texto Sublime Text 2, permitindo uma melhor organização visual dos arquivos. As telas foram estruturadas fazendo-se uso da linguagem HTML 5 e seu design realizado no programa CSS 3. As ações dos botões e da própria tela foram feitas com a utilização do Javascript. Os elementos exibidos na tela possuem a tag "alt", própria do HTML, servindo para descrever imagens e outros recursos, quando estes não podem ser carregados, além de oferecer acessibilidade ao jogador.

Foram utilizados recursos de animação com CSS3 que percorrem toda a introdução do recurso. Nas telas onde o mapa dos lugares é exibido, encontra-se a 
animação das nuvens e, nos balões de texto, foi adicionado um efeito de digitação, onde as letras aparecem uma de cada vez. As instruções terminam com o caractere "|" piscando, indicando que algo está sendo digitado.

Para a transição das telas foram utilizadas funções Javascript, que começam simultaneamente ao carregamento da tela inicial e continuam sendo executadas ao longo da introdução. Dessa forma, é possível controlar o tempo em que cada texto ficará exibido na tela, permitindo que outras telas e elementos sejam chamados para dar continuidade à narrativa.

O protótipo está desenvolvido até a primeira atividade, a qual se passa na biblioteca, onde há uma tela de exercício. O usuário deve estabelecer comunicação com os profissionais dos quatro ambientes previamente mencionados (biblioteca, necrotério do hospital, farmácia e fazenda) levando em consideração o tipo de linguagem a ser utilizada (linguagem culta e formal da língua portuguesa ou internetês). Este exercício foi desenvolvido em Javascript, fazendo-se uso da biblioteca JQuery para auxiliar na lógica e na exibição das mensagens.

\section{Apresentação do OA}

Conforme citado na seção anterior, a partir dos resultados da pesquisa realizada com os alunos, a equipe de design incluiu em sua interface, os elementos que remetem ao gênero terror. Na tela inicial (figura 01), o usuário terá a possibilidade de escolher entre três opções, sendo, a primeira opção de iniciar e começar o jogo.

Já na segunda opção, o usuário observará as informações e os créditos relacionados ao OA. E, no que concerne à terceira opção, o usuário obterá ajuda na dinâmica do Quantium. Vale ressaltar que, no momento em que passar o mouse sobre uma das imagens, surgirá um balão de diálogo acima do ícone com o seu título.

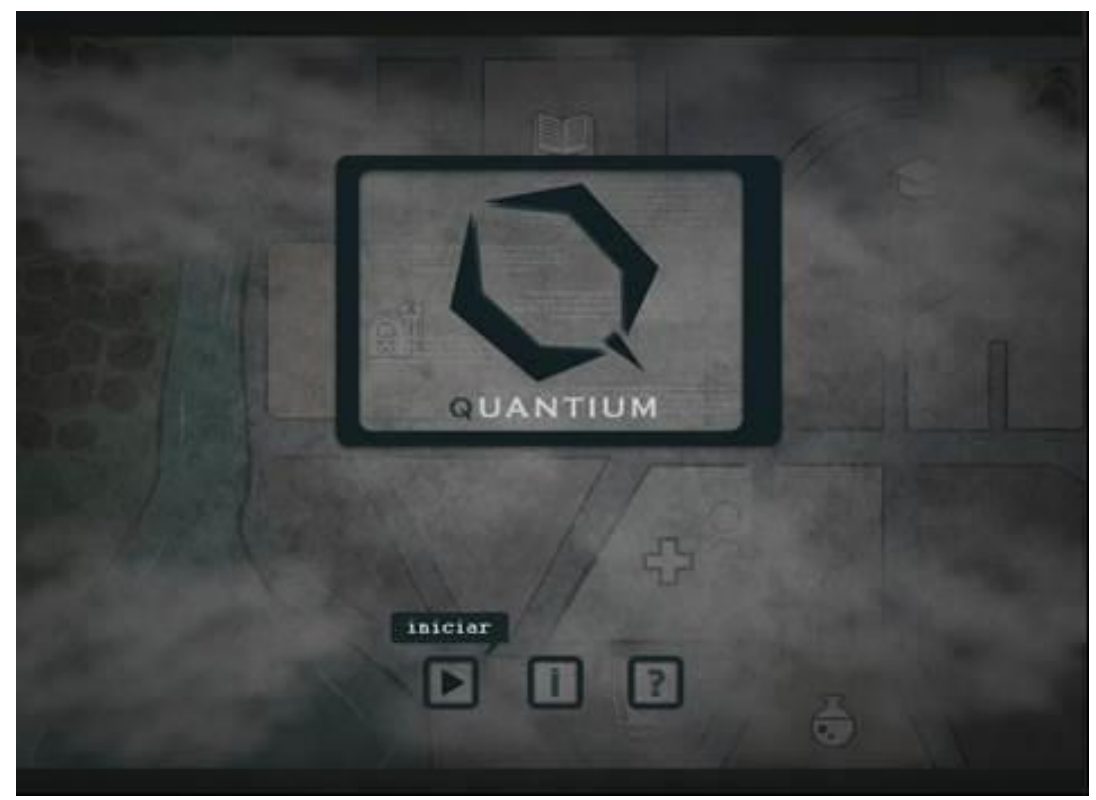

Figura 1. Tela Inicial do Quantium

Após uma explicação sobre o contexto e narrativa do OA, outra tela aparecerá (figura 02) para que o usuário faça seu perfil no jogo. Ele deverá escrever seu nome na caixa preta centralizada e escolher o seu avatar. Existem duas opções de avatar do gênero 
V Congresso Brasileiro de Informática na Educação (CBIE 2016)

Anais dos Workshops do V Congresso Brasileiro de Informática na Educação (CBIE 2016)

feminino e dois avatar para o gênero masculino. Após essas ações, ele deve clicar no botão "OK" para continuar no jogo.

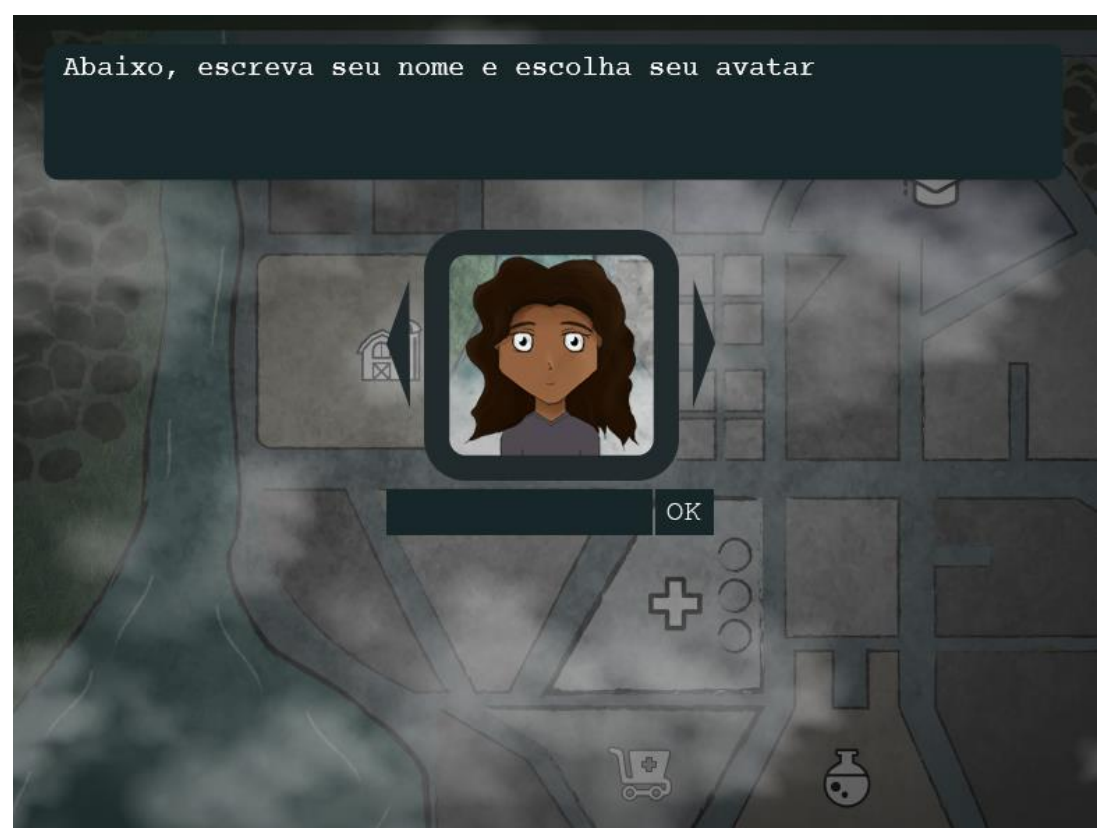

Figura 2. Tela para escrever o nome e escolher avatar

Em seguida, o usuário escolherá o local da cidade para conversar com uma pessoa que esteja naquela localização, através de mensagens instantâneas. Os lugares possíveis são: biblioteca, universidade, fazenda e farmácia.

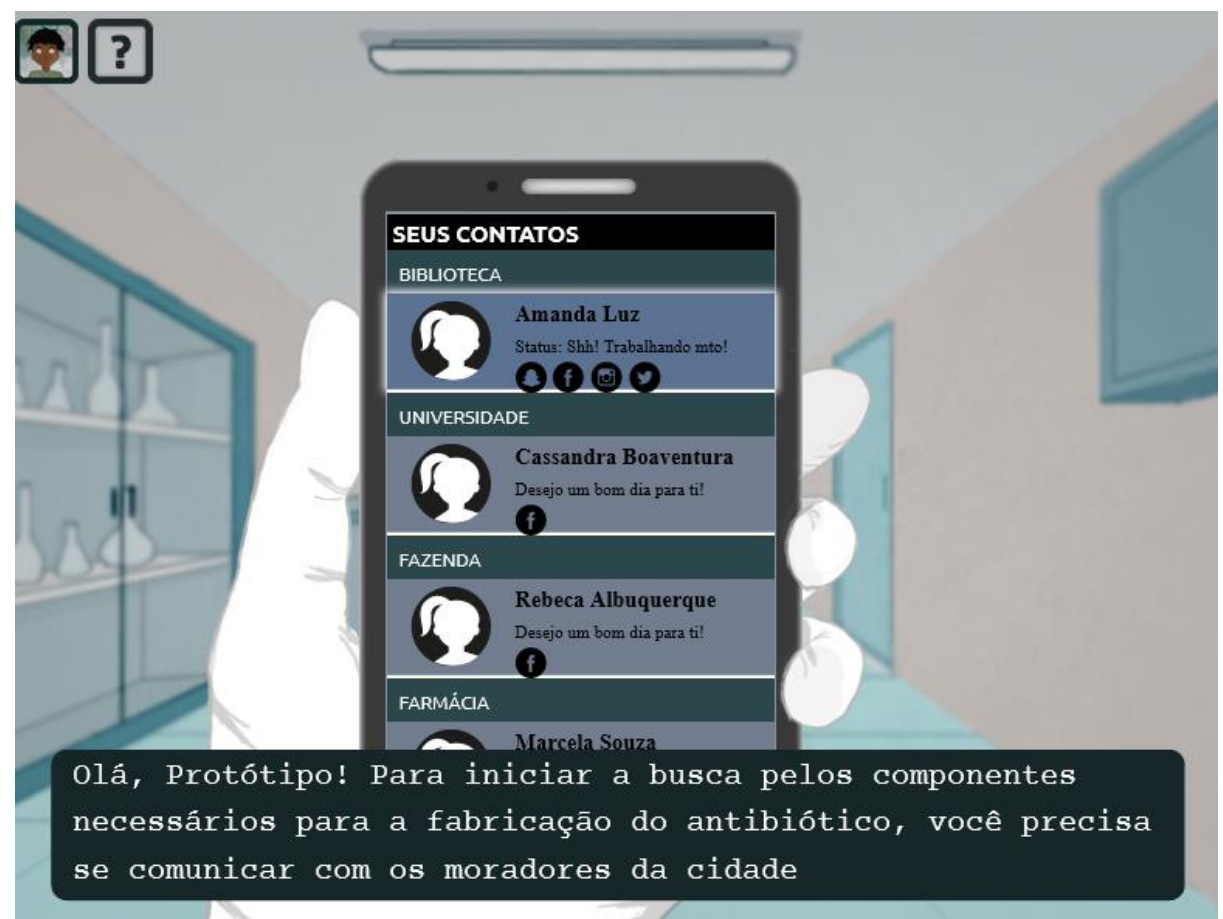

Figura 3. Tela com os locais onde o usuário deve se comunicar com os respectivos profissionais

O usuário começará o jogo na biblioteca. Na biblioteca, o usuário deverá comunicar-se com a bibliotecária através do seu smartphone. O telefone aparecerá na tela e o usuário deverá clicar nas palavras que estão dentro do quadrado azul (figura 4), para completar a frase. 


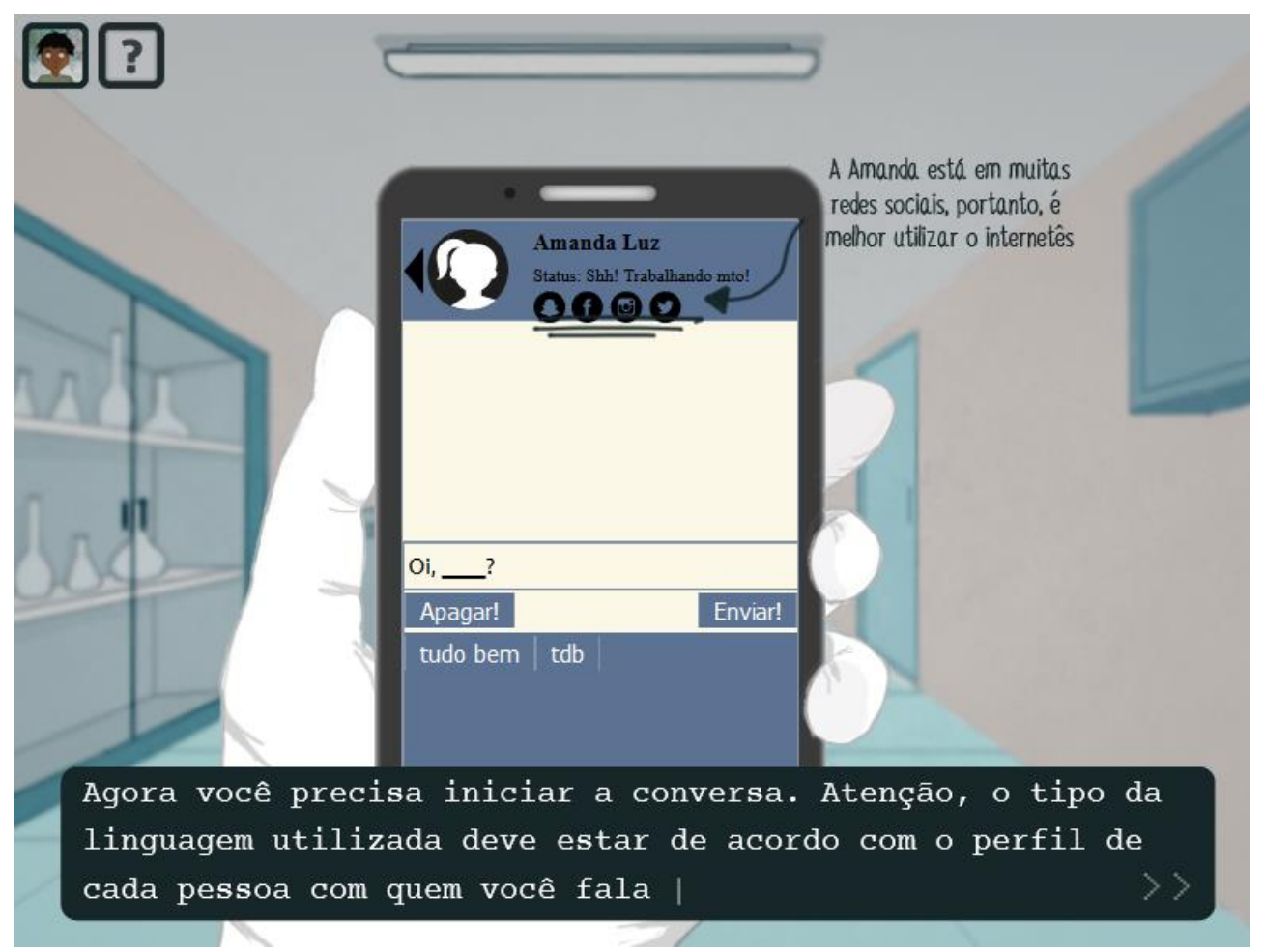

Figura 4. Usuário no laboratório se comunicando com os profissionais

Em cada local, o usuário deverá comunicar-se utilizando o internetês ou a norma culta da língua, dependendo do perfil de pessoa com quem ele está falando. No exemplo da imagem, a bibliotecária participa de muitas redes sociais e utiliza o internetês, portanto, essa deverá ser a linguagem a ser utilizada pelo usuário. Após preencher todas as lacunas, o usuário deve apertar no triângulo ao lado da caixa de mensagem para enviar o conteúdo.

Após concluir a atividade nesse local, os demais locais serão desbloqueados. Como já dito, por apresentar caráter de protótipo, há o desenvolvimento apenas da primeira atividade do Objeto de Aprendizagem (OA), ocorrida na biblioteca. Vale ressaltar a diversidade de atividades presentes nos diferentes locais do OA, possibilitando o trabalho de retextualização e transmutação de gêneros textuais, além do exercício prático de uso do internetês e da norma culta padrão da língua portuguesa.

\section{Considerações finais}

Devido à emergência nas relações de comunicação nos dias atuais, o domínio da língua deve existir e ser aplicado a diferentes usos da linguagem, em diferentes contextos comunicativos. O objeto de aprendizagem em desenvolvimento Quantium surge como forma de trabalhar a linguagem no mundo virtual, propondo a utilização da Língua Portuguesa em seus desdobramentos como linguagem formal e linguagem utilizada na Internet (internetês).

O OA possibilitará ao professor de Língua Portuguesa o trabalho prático com a retextualização, fazendo-se uso da transmutação de gêneros em contextos específicos de aplicação do internetês. Integralmente pensado no público-alvo e nas implicações pedagógicas existentes no universo das escolas públicas, o recurso encontra-se dentro do contexto dos alunos, utilizando-se de gêneros e personagens por eles tidos como favoritos. 
V Congresso Brasileiro de Informática na Educação (CBIE 2016)

Anais dos Workshops do V Congresso Brasileiro de Informática na Educação (CBIE 2016)

O seu desenvolvimento acusa esmero no que concerne as formas de se pensar os usos e aplicações da língua no século XXI, incluindo uma linguagem comum aos jovens $\operatorname{dos} 8^{\circ}$ e $9^{\circ}$ anos, que encontram, no internetês, uma forma de se trabalhar textos dentro de sua realidade. O usuário, ao estabelecer comunicação com diferentes profissionais, em diferentes ambientes no recurso, simula o uso de interlocuções distintas às quais suas escolhas linguísticas resultarão no sucesso ou fracasso das missões sugeridas no objeto de aprendizagem.

O OA encontra-se, ainda, em desenvolvimento, sendo suas atividades produzidas por etapas, fazendo-se uso de avaliações periódicas, vinculando os aspectos pedagógicos, os quais serão utilizados pelo professor, para facilitar o processo de aprendizagem e, aos aspectos técnicos, tornando-o de fácil uso, com um design que reflita o universo dos usuários e boa jogabilidade.

\section{Referências}

Araújo, J. C. (2007) O internetês não é língua portuguesa? Vida e educação, ano 4, n.13, p. 28-29, mar./abr.

Chacon, L. (1998) Ritmo da escrita: uma organização do heterogêneo da linguagem. São Paulo: Martins Fontes.

Crystal, D. (2005) A revolução da linguagem. Tradução de Ricardo Quintana. Rio de Janeiro: Jorge Zahar.

Fusca, C. J. (2008) O processo de abreviação em salas de bate-papo abertas: regularidades e fatores que condicionam seu uso. In: SIMELP I, 2008, São Paulo. In: LimaHernandes, M. C.; Marçalo, M. J. (Org.) A língua portuguesa no mundo. São Paulo: FFLCH/USP, http://www.fflch.usp.br/dlcv/lport/pdf/post/02.pdf

Komezu, F. Tenani, L. (2009). Considerações sobre o conceito de Internetês nos estudos da linguagem. Linguagem em (Dis)curso, Palhoça, SC, v. 9, n. 3, p. 621-643, set/dez. http://www.scielo.br/pdf/ld/v9n3/10.pdf.

Marcuschi, L. A. Gêneros textuais, definição e funcionalidade. In: Dionísio, A. P.; Machado, A . R; Bezerra, M. A. Gêneros textuais \& ensino. $2^{\text {a }}$ ed. Rio de Janeiro: Lucerna, 2003.

Zavam, A.S. Transmutação: criação e inovação nos gêneros do discurso. (2012) Linguagem em (Dis)curso, [S.1.], v. 12, n. 1, p.p. 251-271, http://www.portaldeperiodicos.unisul.br/index.php/Linguagem_Discurso/article/view /869/797. 